\title{
El nuevo Aeropuerto Internacional de la Ciudad de México en el ex lago de Texcoco, Estado de México, problemática socioterritorial y ambiental ${ }^{* *}$
}

\author{
The new International Airport of Mexico City in the former \\ lake of Texcoco, State of Mexico, problematic socioterritorial \\ and environmental
}

O novo Aeroporto Internacional da Cidade do México no antigo lago de Texcoco, Estado do México, problemas socioterritoriaise ambientais

\footnotetext{
* Profesor-Investigador de Tiempo Completo Definitivo. Universidad Autónoma del Estado de México. Centro Universitario UAEM Texcoco.enriquetex132@gmail.com

${ }^{* *}$ El presente artículo inscrito en artículo de reflexión, deriva de la investigación «Indicadores sociales y urbanos en el estudio de la sustentabilidad urbana en Texcoco de Mora, Estado de México», con clave 3707/2014/CID de la Universidad Autónoma del Estado de México, mismo que concluyó en el año 2016. Artículo recibido el o3-04-2017 y aprobado 17-01-2018.
} 


\section{Cómo citar}

MoReno SÁncheZ, E. (2018). El nuevo Aeropuerto

Internacional de la Ciudad de México en el ex lago de Texcoco, Estado de México, problemática socioterritorial y ambiental.

Revista CS, (26), 203-235.

DOI: https://doi.org/10.18046/recs.i26.2396 
Resumen

Abstract

Resumo

El nuevo Aeropuerto Internacional de la Ciudad de México se construye en terrenos de lo que fuera el Lago de Texcoco; existe un problema de ordenamiento socioterritorial y ambiental en la consolidación de la obra, que no estaba programada o considerada en los planes de ordenamiento urbano en el orden local, estatal o federal, lo cual permite conocer la falta de coordinación entre los distintos órdenes de gobierno, así como la carencia de planificación adecuada para estas megaobras urbanas. Lo que existe a la fecha es un cambio de uso de suelo no autorizado por el gobierno local en una zona de mitigación y rescate ecológico, ahora convertido en zona urbana donde se ubicará el megaproyecto más importante realizado en México en los últimos cuatro decenios. Este trabajo explica las contradicciones socioterritoriales y ambientales que son parte de las dimensiones de estudio que se nutren con entrevistas e información documental con una perspectiva analítica, con el objetivo de conocer problemáticas asociadas con el nuevo Aeropuerto Internacional de la Ciudad de México y que se construye en un polígono de lo que fue el Lago de Texcoco en el Estado de México.

PALABRAS CLAVE:

Lago de Texcoco; Aeropuerto Internacional; México

The New International Airport of Mexico City is being built on lands outside Lake Texcoco. There is a socio-territorial and environmental planning problem in its construction. This project is not programmed or considered in the urban planning design of local, state or federal order, which allows us to know the lack of coordination between the different urban macro projects. At this moment, there is a change of land use not authorized by the local government, an area of ecological mitigation and rescue, which is now converted into an urban area where will be located the most important urban mega-project in Mexico in the last four decades. This work contains the explanation of the socio-territorial and environmental contradictions that are part of the dimensions of study. They are nour- 
O novo Aeroporto da Cidade do México é construído em no antigo Lago de Texcoco; há um problema de ordenamento socioterritorial e ambiental na consolidação da referida construção. Essa obra de infraestrutura não foi programada ou considerada nos planos de ordenamento urbano na ordem local, estadual ou federal, o que permite conhecer a falta de coordenação intergovernamental entre as diferentes ordens de governo, bem como a falta de planejamento para esse megaprojeto urbano. O que existe até hoje é a mudança no uso da terra não autorizada pelo governo local em uma área de mitigação e corredor ecológico, agora convertida em uma área urbana onde o megaprojeto mais importante do México nas últimas quatro décadas estará localizado. $\mathrm{O}$ artigo contém uma explicação das contradições socioterritoriais e ambientais que fazem parte das dimensões do estudo que são alimentadas com entrevistas e informações documentais com uma perspectiva analítica, com o objetivo de conhecer os problemas associados ao novo Aeroporto da Cidade do México que constrói-se sobre um polígono no antigo Lago de Texcoco, no Estado no México.

PALAVRAS CHAVE:

Lago de Texcoco; Aeroporto internacional; México 


\section{Introducción}

Se ha iniciado la construcción del Nuevo Aeropuerto Internacional de la Ciudad de México (NAICM), el megaproyecto urbano más importante del gobierno federal en el periodo 2012-2018, y seguramente uno de los más significativos de las últimas cuatro décadas. Será el proyecto que trascienda el sexenio gubernamental, asociado a la construcción de grandes obras urbanas en una zona del antiguo Lago de Texcoco, donde se ubica el cuerpo de agua más importante de la ZMCM, el Lago «Nabor Carrillo», lacustre artificial construido hace más de tres décadas, además de una serie de proyectos ecológicos y ambientales de trascendencia para la Ciudad de México y el entorno metropolitano. Así, el referido proyecto urbano, se torna relevante para la investigación académica y social.

En casi dos décadas distintos gobiernos federales han insistido en la necesidad de construir un nuevo aeropuerto, pues el actual tiene más de medio siglo, es insuficiente y requiere nuevas pistas de aterrizaje, nuevas terminales, nuevos accesos y nueva infraestructura que permita atender la creciente demanda del movimiento de personas y mercancías en el contexto de la inserción de la economía mexicana al proceso de globalización.

En el municipio de Texcoco se construye gran parte del NAICM; este municipio es parte integrante de la Zona Metropolitana de la Ciudad de México (ZMCM), también de la Zona Metropolitana del Valle de México $(Z M V M)^{1}$ y de la megalópolis más grande de México y de Latinoamérica. En esta área se registran los procesos más intensos de urbanización y de degradación ambiental; sus efectos son evidentes y es uno de los problemas que de manera constante se observan en el municipio motivo de la investigación y en la región.

Hablar del nuevo aeropuerto es asociarlo al municipio de Texcoco, a la periferia metropolitana, a las formas de modificación de lo rural y lo urbano, a la modificación de los recursos naturales, al proceso de desecar una parte de lo que fuera el Lago de Texcoco. También a los procesos de las llamadas ciudad-región (Eibenschutz, 2013), a las grandes megalópolis del mundo, a los problemas socioespaciales y territoriales,

\footnotetext{
1. En el año 2010, la Zona Metropolitana de la Ciudad de México, según el Instituto Nacional de Estadística y Geografía (INEGI), comprendía la misma Ciudad de México y sus 16 delegaciones, más 27 municipios conurbados del Estado de México y el municipio de Tizayuca en el Estado de Hidalgo, con una población estimada de 17 millones de habitantes en dicha región. También existe otra demarcación y división administrativa llamada Zona Metropolitana del Valle de México (ZMVM), que es más amplia y abarca 59 municipios del Estado de México, 16 delegaciones de la Ciudad de México y 29 municipios del Estado de México, más el municipio de Tizayuca, del Estado de Hidalgo, con lo cual se complejiza la región, ya que comprende 21'163.226 pobladores, según lo establece el criterio de Sedesol, Inegi y Conapo en el documento Zona Metropolitana del Valle de México, editado por el Gobierno del Estado de México/Coespo (2009).
} 
y a una entidad distinta a la que actualmente alberga el aeropuerto de la Ciudad de México, llamado oficialmente Aeropuerto Internacional «Benito Juárez», que se ubica en la delegación Venustiano Carranza, y que en el futuro se ubicará en una demarcación político-administrativa distinta, es decir, en el Estado de México, y en otro territorio como el municipio de Texcoco de Mora.

El objetivo de este trabajo es conocer de mejor manera el efecto que tendrá la construcción del nuevo Aeropuerto Internacional de la Ciudad de México en terrenos de lo que fuera el Lago de Texcoco, municipio de Texcoco, Estado de México.

Este artículo se organizó en tres partes. La primera presenta la problemática; posteriormente se analiza la importancia de la construcción del NAICM en terrenos del Lago de Texcoco, se nutre con distintas entrevistas realizadas e información documental y trabajo de campo; y finalmente se presentan las conclusiones del trabajo desarrollado.

\section{Problemática}

La problemática de la construcción del NAICM tiene dos variables a estudiar. La primera tiene que ver con la relación que guarda el citado proyecto en una zona de mitigación y rescate ecológico, decretada por el gobierno de la República y también conocida como «zona federal». En dicha zona se está construyendo el megaproyecto urbano más importante en más de cuatro décadas en México. No se puede negar que el lago de Texcoco fue el cuerpo de agua más importante del Valle de México, y formó parte de la estructura del sistema hidrológico de toda una cuenca. Con el tiempo, el lago se fue desecando y se generó una serie de problemas de mayor complejidad ambiental, ecológica y social que afecta a toda una metrópoli. Conagua (2007) identifica las siguientes problemáticas:

La desecación del lago y la desertificación de los terrenos circundantes, en combinación con los vientos dominantes, provocaron la formación de tormentas de polvo (tolvaneras).

Las descargas de aguas residuales en el lecho desecado generaron un foco de insalubridad.

En la Cuenca Tributaria Oriental, la deforestación y la pérdida de cubierta vegetal, provocaron la erosión de los suelos y corrientes torrenciales que causaban desbordamientos e inundaciones. 
La sobreexplotación de los acuíferos modificó la estructura del suelo, lo que, sumado a sus propias características geomorfológicas, originó agrietamientos y hundimientos que provocaron que la elevación del lecho del Lago fuera mayor que la de la Ciudad de México (Conagua, 2007: 16).

Por lo anterior surgen las preguntas: ¿Cuál es la problemática de construir el NAICM en terrenos del Lago de Texcoco? ¿El tema es un asunto ambiental o tiene que ver con el proceso urbano-ambiental de la Zona Metropolitana más importante del país? ¿NAICM es una necesidad de la mayor importancia para el desarrollo del país? Son preguntas que ayudan a guiar la investigación desarrollada y que permiten reflexión acerca de la temática que se ha tornado la gran obra urbana en un área de reserva ecológica, y del proyecto ambiental que existe en el Lago de Texcoco con las mayores consideraciones técnicas-científicas y de impacto ambiental y social en Texcoco, en la región y megalópolis del centro del país.

La problemática de construir el megaproyecto del aeropuerto en terrenos de un lago se integra con las siguientes consideraciones:

1) La zona donde se ubica la construcción del NAICM se encuentra en la Zona Metropolitana del Valle de México (ZMVM), misma que contaba con más de 20 millones de habitantes y comprende 59 municipios del Estado de México, 16 delegaciones del Distrito Federal (hoy llamada Ciudad de México), y un municipio de Tizayuca, Hidalgo (OCDE, 2015). Es una zona donde el tema del agua, del drenaje, la basura y los desechos sólidos toma relevancia y complejidad, ya que intervienen tres entidades y distintos órdenes de gobierno, con distintas divisiones político-administrativas: caso concreto el Estado de México y la Ciudad de México, dos entidades con legislaciones diferentes en materia urbana, ambiental y constitucional; por ejemplo la Ciudad de Méxicoelaboró nueva Constitución para la Ciudad, y el Estado de México tiene la suya desde hace más de un siglo. Según la misma Organización para la Cooperación y el Desarrollo Económico (OCDE) y la Organización de las Naciones Unidas (ONU) es una de las cuatro Zonas Metropolitanas más grandes del mundo después de las de Tokio-Osaka en Japón, Delhi en India, Shangái, China y la Ciudad de México y su zona Metropolitana (OCDE, 2015 y ONU, 2014).

Si bien el crecimiento de la población se ha desacelerado notablemente en el Valle de México, durante la última década promedió 1,2 \% anual y la población en las zonas periféricas creció más rápido que la del núcleo urbano. Esto se sumó a la expansión de la zona urbana, por lo que se incrementó la necesidad de mejor y mayor infraestructura urbana. Afortunadamente, al expandirse la zona urbana no se ha reducido la densidad 
urbana. En comparación con ciudades europeas u otras ciudades latinoamericanas, el Valle de México mantiene una población bastante densa de 13500 habitantes por km2 (OCDE; 2O15: 4).

2) También la ZMVM es el centro económico, financiero, político y cultural de México; por tanto el NAICM es indispensable en dicha zona. Los flujos de movimientos, mercancías y personas son los mayores de Latinoamérica, lo que conlleva generar nuevo ordenamiento urbano-ambiental que brinde certeza a los procesos productivos, de inversión y de empleo, para el mismo Valle de México y su zona metropolitana.

Uno de los factores típicamente territoriales; es decir, que dependen fuertemente de su arreglo en el territorio, es la actividad económica. Las economías y externalidades de las actividades productivas están muy asociadas con su localización. Por ello, ordenar el territorio para preservar y desarrollar la producción de las metrópolis y sus regiones es condición central de la competitividad de cada sector y de la metrópoli como un todo (Iracheta, 2009: 114).

«El Valle de México representa el $17 \%$ de los habitantes y el $18 \%$ de los empleados de México, quienes producen el 23\% del PIB del país» (OCDE, 2015:7). Se considera que el mismo Valle de México no logra una adecuada proporción de porcentaje de población, producto interno bruto y empleo. No existe una adecuada proporción entre estas tres variables que son importantes para una metrópoli.

Como resultado, entre las 275 zonas metropolitanas de la OCDE, el Valle de México se mantiene en el 10 \% con el PIB per cápita más bajo. En 2010, el PIB per cápita promedio en el Valle de México fue de USD 16.060, cifra que no refleja las marcadas variaciones entre los niveles de la Ciudad de México (USD 26.550) y los municipios del estado de México (USD 7.140) (OCDE, 2015:7). Es decir, existe diferencia significativa en el Índice de Desarrollo Humano (IDH), el cual comprende, entre otras cosas, el ingreso, la salud y la educación. La diferencia entre vivir en ciertas delegaciones de la Ciudad de México, como San Ángel, colonia Nápoles, colonia del Valle y vivir en colonias y municipios del estado de México como Ecatepec es notoria: es el más inseguro del Valle de México y colindará con el polígono del aeropuerto. En el mismo polígono se ubica el municipio de Atenco (conocido en el pasado por el conflicto del pago de parcelas) y con pobreza e IDH más deficiente que varias delegaciones y colonias de la Ciudad de México, y que también tendrá vecindad con el citado aeropuerto. El municipio de Texcoco con su Índice de Desarrollo Humano es mejor que los municipios de la región y que el promedio del Estado de México. Sin embargo su ingreso promedio aún es bajo, pues más del $60 \%$ percibe ingresos 
entre 2 y 3 salarios mínimos para la Población Económicamente Activa (PEA); es decir, la mayoría de la población es pobre por el ingreso percibido (Coneval, 2011).

Una adecuada proporción para vivir con mejor IDH y calidad de vida es contar con ingresos superiores a los 26.500 dólares americanos per cápita; es decir, equivalente al ingreso per cápita de la Ciudad de México; además contar con variables como salud, educación e ingresos, los cuales las Naciones Unidas (PNUD) considera como indispensables. De acuerdo al IDH, los municipios que colindan con el polígono del NAICM son: Atenco, Texcoco, Ecatepec, Chimalhuacán, y Nezahualcóyotl. Texcoco es considerado de nivel alto, luego el resto se ubica en condiciones de índice de desarrollo humano medio por las condiciones citadas. También se considera que los municipios de mayor número de personas pobres, que no es lo mismo que el más pobre, pero que concentran un número grande de pobres es Ecatepec de Morelos con 723.559 personas (40,8\%) que colinda al norte con el NAICM; luego está Nezahualcóyotl que tiene registro de 462.405 (38,8\%), luego Chimalhuacán que tiene registro de 261.496 personas $(62,7 \%)$; estos dos últimos colindarán al sur del NAICM. En pobreza extrema y con mayor número de personas se ubica Ecatepec de Morelos con 107.023 personas (6\%), Chimalhuacán con registro de 57.149 personas $(13,7 \%)$ y Nezahualcóyotl con 56.653 personas $(4,7 \%)$. Texcoco por su parte tuvo registro en pobreza extrema de 21.223 habitantes en el 2010; en pobreza 90.998 personas, que equivale al $34 \%$ de la población. El municipio de Atenco reportó 26.612 individuos (58,6 \% del total de la población) que se encontraban en pobreza, y en pobreza extrema 5.602 personas (12,3\%) (Coneval, 2011 y 2012). El siguiente cuadro expresa las condiciones señaladas:

\begin{tabular}{|l|l|}
\hline TABLA 2 & $\begin{array}{l}\text { Municipios que presentan condición de pobreza y pobreza extrema } \\
\text { y colindan al NAICM }\end{array}$ \\
\hline
\end{tabular}

\begin{tabular}{|c|c|c|c|}
\hline Municipio & Total de población & En pobreza & En pobreza extrema \\
\hline Ecatepec & $1^{\prime} 677.678$ & $723.559(40,8 \%)$ & $107.023(6 \%)$ \\
\hline Atenco & 62.392 & $26.612(58,6 \%)$ & $5.602(12,3 \%)$ \\
\hline Texcoco & 240.749 & $112.221(42 \%)$ & $21.223(8 \%)$ \\
\hline Chimalhuacán & 679.811 & $261.496(62,7 \%)$ & $57,149(13,7 \%)$ \\
\hline Nezahualcóyotl & $1^{\prime} 039.867$ & $462.405(38,8 \%)$ & $56,653(4,7 \%)$ \\
\hline Total & 3'700.497 & 1'565.070 & 247.650 \\
\hline
\end{tabular}


«En 2010, de acuerdo con cifras de Coneval, a nivel nacional la población en pobreza $^{2}$ fue de 52,1 millones de personas y 12,8 millones en pobreza extrema, ${ }^{3}$ lo que representó respectivamente el 46,3 y el 11,4 por ciento del total de población» (Coneval, 2012). Esto da una idea del significado que se tiene con esta dimensión de estudio, donde existe zona urbana con alta densidad poblacional y con creciente desigualdad económica y social entre habitantes de los distintos municipios que colindan con el NAICM.

Según datos estadísticos de Coneval (2016), en el periodo 2010-2015 existe aumento del número de pobres en total y en porcentaje en todos los municipios que colindan con el polígono del NAICM, y que la pobreza extrema tienda a disminuir en porcentaje y en número en todos los municipios antes citados. Existen diferencias marcadas en el mismo Valle de México, en su zona metropolitana y en la región; la evidencia documental basada en estadística oficial así lo manifiesta. En general, es mejor vivir en ciertas colonias o delegaciones de la Ciudad de México que en el Estado de México. El ingreso, la salud y la educación son determinantes para tener una adecuada calidad de vida en la metrópoli y megalópolis más importante del país y de Latinoamérica.

3) «La desertificación del Valle de México ha sido originada por la devastación de los bosques, la erosión de los suelos y el abatimiento de los acuíferos, debido a la sobre explotación por la operación de casi 4,ooo pozos existentes en el Valle de México» (Conagua, 2007:38).

Encinas (2015) considera que:

El lago de Texcoco cuenta con una superficie de 10 mil hectáreas que forman parte de la Cuenca Hidrológica del Valle de México, situada en el centro del eje Neovolcánico que atraviesa el territorio nacional desde la costa del Pacífico hasta el Golfo de México y parte fundamental del sistema y funcionamiento hidrológico de la cuenca. Al desecarse el Lago, ocurrieron una serie de tensiones ambientales que desembocaron en

2. Pobreza. Una persona que se encuentra en situación de pobreza cuando tiene al menos una carencia social (en los seis indicadores de rezago educativo, acceso a servicios de salud, acceso a la seguridad social, calidad y espacios de la vivienda, servicios básicos en la vivienda y acceso a la alimentación) y su ingreso es insuficiente para adquirir los bienes y servicios que requiere para satisfacer sus necesidades alimentarias y no alimentarias (Coneval, 2012).

3. Pobreza Extrema. Una persona se encuentra en pobreza extrema cuando tiene 3 o más carencias, de 6 posibles, dentro del Índice de Privación Social y que además se encuentra por debajo de la línea de bienestar mínimo. Quien se encuentra en esta situación dispone de un ingreso tan bajo que, aun si lo dedicara por completo a la adquisición de alimentos, no podría adquirir los nutrientes necesarios para tener una vida sana (Coneval, 2012). 
serio deterioro ecológico, como la desertificación creciente de los terrenos ocupados y circundantes (Encinas, 2015: 47).

Al revisar y analizar el Programa Nacional de Desarrollo Urbano 2014-2018 (Secretaría de Gobernación, 2014), el Programa de Ordenación de la Zona Metropolitana del Valle de México (POZMVM) del 2011, y en el ámbito estatal el Plan Estatal de Desarrollo Urbano (PEDU) del 2005, los dos Planes Regionales de Desarrollo Urbano del Valle de Toluca y del Valle Cuautitlán-Texcoco, así como los planes municipales de desarrollo urbano con más de una década de vigencia en el caso de Texcoco y los municipios vecinos al polígono del aeropuerto, no se encuentran evidencias documentales que consideren al megaproyecto urbano del NAICM; es decir, nunca estuvo considerado en la normatividad o documento oficial en los distintos órdenes de gobierno. Se observa que los grandes proyectos de desarrollo urbano en las grandes zonas metropolitanas no se encuentran inscritos en los instrumentos de planeación, de ordenación urbana-ambiental y de financiamiento en los municipios en México.

Para complementar este apartado se comparte parte de la entrevista realizada a Gabriel Quadri, que entre sus últimas tareas se desempeñó como Diputado Constituyente en la Ciudad de México en el periodo 2016-2017.

Contar con plan maestro que integre todos los componentes urbanos hidrológicos, aeroportuarios, de transporte, de accesibilidad, de desarrollo urbano, un plan maestro, que trate de cambiar y adecuar, y lograr convergencia con los programas de desarrollo urbano, no sólo del Distrito Federal, sino de los municipios de Texcoco, de Ecatepec, Chimalhuacán. Que sea un todo coherente en materia urbana. Hay un grave problema, porque como sabemos, nuestro artículo 115 Constitucional le da todas las facultades, en materia de regulación del suelo, al municipio, y también al Estado de México. Hay que crear algo distinto que permita romper esa inercia federalista, que en éste y en otros casos ha sido una verdadera tragedia para este país, como sabemos con hechos recientes. Realmente hay que darle facultades ejecutivas, regulatorias en muchos sentidos, de desarrollo a este nuevo vehículo institucional. Creo que ese es el gran reto por ahora, un Plan Maestro (Quadri, comunicación personal, 27 de Noviembre 2014).

La gran demanda de uso de suelo urbano en propiedad privada y ejidal será de los retos que en las próximas décadas tendrán que enfrentar los municipios metropolitanos cercanos a la gran ciudad de México. En los próximos decenios del siglo XXI esta región será una extensión de la ciudad con sus contradicciones de una mayoritaria población urbana. La presión se sentirá en gran medida en los gobiernos locales y la oferta de suelo tenderá a hacerse más escasa y con mayor presión por los núcleos 
poblacionales que seguirán migrando a la periferia de la Ciudad de México, creando las llamadas ciudades «satélites». Texcoco y la región no están ajenas a la tendencia de urbanización que presenta el país y las zonas metropolitanas más importantes de la nación, pero también Texcoco y la región pueden integrarse a un circuito de zonas competitivas e importantes en la distribución del crecimiento económico del país. Sin embargo, el impacto de las grandes obras urbanas en México se asocia a grandes desigualdades; ejemplo son los desarrollos urbanos, que en el caso de México han mostrado un desorden urbano en gran parte del territorio. Uno de los ejemplos en la ZMCM es la zona de «Santa Fe» en la ciudad de México y la Zona de «Huixquilucan», en el Estado de México, ubicado en el poniente de dicha Zona Metropolitana, donde existe número importante de usuarios del actual aeropuerto internacional de la Ciudad de México.«La Comisión Nacional del Agua (Conagua) fue creada el 16 de enero de 1989 por Decreto Presidencial en el Diario Oficial de la Federación, en calidad de órgano desconcentrado de la entonces Secretaría de Agricultura, Ganadería y Recursos Hidráulicos» (Conagua, 2012: 1). Lo que queda del Lago de Texcoco está reducido a casi 12 mil hectáreas que están bajo resguardo de la Conagua, dependencia descentralizada de la Administración Pública Federal. Es una zona territorial que de manera oficial está destinada a ser un Proyecto de Mitigación y Rescate Ecológico en lo que fuera el Lago de Texcoco. El Reglamento Interior de Conagua, publicado en el Diario Oficial de la Federación del 30 de noviembre de 2006, establece en el artículo 67 lo siguiente:

De lo cual deviene la participación de la Subdirección General de Agua Potable, Drenaje y Saneamiento, así como del Organismo de Cuencas y Aguas del Valle de México, para atender la problemática que representa el Lago de Texcoco ubicado en la Cuenca del Valle de México, tomando en consideración las conclusiones y recomendaciones informadas por el Instituto Mexicano de Tecnología del Agua, en el sentido de que el proyecto es factible técnicamente en lo referente a lastecnologías de pastización, y cortinas rompevientos con el apoyo de sistemas de riegoy drenaje; como estrategia para disminuir, mitigar o controlar las tolvaneras con las que se emiten partículas a la atmósfera, ya que las acciones propuestas en este componente se sustentan en los métodosy técnicas empleadas con éxito desde 1971 en el Programa de Rescate Hidrogeológico del Lago de Texcoco (Conagua, 2012: 3).

El proyecto de Conagua es una zona de mitigación y rescate ecológico y las dependencias del gobierno federal deberán observar las disposiciones del citado Decreto del Ejecutivo Federal. No ha existido nuevo decreto que modifique tal situación, 
pues los decretos del Ejecutivo Federal que existieron en el año $2001^{4}$ quedaron sin efecto, pues el proyecto del aeropuerto suspendido por el ex Presidente Vicente Fox (2001-2006) no concluyó la litis que existía con los campesinos ejidatarios de los municipios de Atenco y Texcoco, y el conflicto social que derivó la propuesta del aeropuerto en dicho lugar. Ahora el inicio de la cuestionada y polémica megaobra urbana es una realidad y desde el año 2015 ha empezado su construcción; la diferencia es que ahora no existió expropiación, como en el año 2001, que afectaba a núcleos ejidales de los municipios de Atenco, Texcoco y Chimalhuacán, sino que poco a poco, y durante más de una década se han ido adquiriendo las parcelas o terrenos ejidales a los poseedores de la tierra con otra oferta de precio que supera en promedio más de 10 veces el precio original a través de la Conagua, con la idea de ampliar la Zona Federal del Lago de Texcoco y generar un proyecto ecológico de mayor dimensión y magnitud. Por un lado existe Decreto Federal para una Zona de Mitigación y Rescate Ecológico, y ahí mismo se construye el más grande aeropuerto de Latinoamérica; es decir, una obra urbana dentro de una zona de importancia ambiental y ecológica para el Valle de México que se encuentra en parte de territorio texcocano.

No se puede perder de vista que el capital natural o los recursos naturales son determinantes de las posibilidades productivas de una sociedad a través de su papel como insumos en el proceso económico; pero también el capital natural presta servicios en la función de sumidero de los residuos de las actividades productivas y consuntivas de una sociedad (Constantino, 2007: 57).

Por un lado existe una racionalidad sustentada en el crecimiento de una economía con efectos depredadores de los recursos naturales, tanto en el contexto de las economías globalizadas como las que están en vías de desarrollo y dependientes. Por el otro lado, existe la herencia cultural, la identidad, la diversidad étnica, la histórica, la ambiental, la política y la social de municipios como Texcoco; sin embargo, este municipio y la región está vinculada a los procesos urbanos, ambientales que existen en la metrópoli más importante de México.

4. El 22 de octubre de 2001 se publicó en el Diario Oficial de la Federación el Decreto que establece desarrollar el proyecto aeroportuario en Texcoco y su zona de regulación ecológica para el Valle de México. Son los municipios de Texcoco, Atenco y Chimalhuacán, así como un área del ex vaso del Lago de Texcoco los espacios territoriales afectados (4.50o hectáreas). El proyecto fue conocido en el año 2001 y 2002 como el proyecto aeroportuario de «Texcoco». 
El Lago de Texcoco fue el cuerpo de agua más importante del Valle de México, así como una parte fundamental del sistema y funcionamiento hidrológico de la cuenca. La Gran Tenochtitlán, antecedente de la Ciudad de México, se estableció en el lago de Texcoco. Las alteraciones ambientales resultado de su desecación provocaron un serio deterioro ecológico; el lecho lacustre quedó expuesto y se desertificaron los terrenos circundantes, lo que generó un grave foco de insalubridad que afectó la salud de la población de la Ciudad de México (Conagua, 2007: 15).

El NAICM se construye en la llamada «zona federal», que se encontraba bajo resguardo por la Comisión Nacional del Agua (Conagua) dependiente de la Secretaría del Medio Ambiente y Recursos Naturales (Semarnat) del gobierno federal y ahora tiene la posesión de una parte del terreno la Secretaría de Comunicaciones y Transportes (SCT), así como la dependencia llamada Grupo Aeroportuario de la Ciudad de México, S.A de C.V (GACM).

La extensión de la actual zona «federal» es de 12.363 ha (Conagua, 2015), lo cual no significa que todo sea territorio del municipio de Texcoco; por ejemplo, en el límite con la caseta de cuota Peñón, cercano al relleno sanitario del bordo poniente o tiradero de residuos sólidos, pertenece a la jurisdicción política-administrativa del municipio de Nezahualcóyotl. Los predios que el gobierno federal a través de Conagua ha ido adquiriendo son las comunidades de Tocuila, San Felipe, Santa Cruz de Abajo y la Magdalena Panoaya, todas de manera cercana al polígono del nuevo aeropuerto, y aún continúa. Se calcula que hasta finales del 2018 o mediados del 2019 concluirá la etapa de predios adquiridos por el gobierno federal que no necesariamente serán utilizados en la construcción del NAICM. Aún no se tiene el dato exacto del total de predios adquiridos y que serán parte de la zona federal; sin embargo, se estima que se han adquirido más de 400 hectáreas en estas comunidades en la última década.

Es preciso señalar qué es una «zona federal» dentro de un territorio local. Todo el país es una federación constituida por estados o entidades y municipios en un pacto federal autónomo y soberano. La Constitución de los Estados Unidos Mexicanos, en su artículo 115, establece las facultades y alcances del municipio, se reconoce en su fracción $\mathrm{V}$ que podrán formular, aprobar y administrar la zonificación y planes de desarrollo urbano municipal, también faculta para intervenir en la regulación de la tenencia de la tierra urbana, otorgar licencias y permisos para construcciones, participar en la creación y administración de zonas de reserva ecológica y en la elaboración y aplicación de programas de ordenamiento en esa materia. Por su parte, la Ley General de Asentamientos Humanos de 1993, en sus artículos 7, 8, 9, 12, 20, 21, 22, 24 y 25, especifica los conceptos y alcances de los términos de aplicación vinculante. Con la nueva Ley se afinó el principio de concurrencia de los tres órdenes 
de gobierno, se normó la competencia municipal en materia de desarrollo urbano, se trató de compatibilizar medio ambiente y urbanización, se simplificó el tratamiento de las conurbaciones y, lo más importante, se instituyó la zonificación en sustitución de las declaratorias como instrumentos de regulación (Rivero y Moreno, 2017: 40).

Entonces el gobierno local tiene injerencia en las decisiones que se tomen en su territorio, y en este caso no se puede decir que la «zona federal» sea asunto exclusivo del gobierno federal, son distintos órdenes de gobierno que participan en un megaproyecto urbano en un territorio municipal, pues no hay territorios federales, todo el país está integrado por municipios, estados y delegaciones, tal es el caso de este último, la Ciudad de México. Existen gobiernos local o municipal, estatal y federal; no existe en la Constitución superioridad de uno u otro, todos son gobiernos con facultades y atribuciones establecidas en la Constitución de México, y en las Constituciones de cada estado del país. Una cosa es que parte de los terrenos del ex Lago de Texcoco estén bajo resguardo o dominio del gobierno federal y sus dependencias de la administración pública en territorio municipal, y otra cosa es que sea patrimonio o bien del gobierno federal; es una situación con implicaciones jurídica-legales, de acciones y tareas que en el pasado lo tuvo Conagua, como órgano descentralizado de la Administración Pública Federal; pero ahora intervienen otras dependencias como la SCT y GACM.

También es importante recordar que en el año 2002, el gobierno local de Texcoco interpuso Controversia Constitucional por el uso del suelo vs el gobierno federal y su representante máximo que es el ejecutivo federal; pues uno de los argumentos ya explicados fue la facultad expresa en el artículo 115 de la Constitución mexicana para el caso del municipio y su facultad jurídica establecida. En analogía, es lo que sucede con el actual aeropuerto de la Ciudad de México, bajo resguardo del gobierno federal pero con la participación de ciertas tareas y actividades del gobierno de la ciudad. Así mismo, el gobierno de la Ciudad de México ha manifestado que es necesario el estudio y el análisis del destino que tendrá el terreno del actual aeropuerto cuando concluya sus operaciones, mismas que se estima posterior al año 2020, donde nuevamente la Ciudad tendrá dominio sobre las casi 700 hectáreas del terreno que sirve al actual aeropuerto.

Es de señalar que a finales del siglo XX el famoso lago de Texcoco dejó de existir y se convirtió en terrenos ocupados por la llamada Comisión Lago de Texcoco (CLTEX), organismo público descentralizado dependiente de Conagua. La disminución de la zona lacustre fue avanzando con los siglos: en el siglo XVI, el lago era inmenso y comprendía más del 50 \% de la Ciudad de México, y sus orillas llegaban de manera cercana al centro de la ciudad. La pérdida progresiva de la zona lacustre se debió a dos factores importantes: 1) Al crecimiento urbano natural y a las polí- 
ticas públicas que alentaron el cambio de uso de suelo, de ser terrenos salitrosos a terrenos para la vivienda, industria y comercio; 2) a la decisión del Estado de ir repartiendo el terreno en nuevas zonas urbanas que no existían, los terrenos del Lago de Texcoco fueron el pretexto para crear ciudades; ahí se encuentra la llamada Ciudad Nezahualcóyotl, que hace un siglo no existía y hoy es una ciudad de más de un millón de habitantes, misma que presenta colindancia y conurbación con la Ciudad de México en su parte oriente. También está el caso de terrenos que eran parte del Lago de Texcoco y ahora son parte de municipios como el caso Ecatepec, Chimalhuacán y Colonias, cercanos al aeropuerto, densamente poblados y que no existían en el siglo XX. Fueron decisiones que involucraron a los distintos órdenes de gobierno: federal, estatal y municipal, y con escasa participación de la sociedad civil en la decisión de cómo utilizar la zona lacustre del Lago de Texcoco. «El tejido urbano se ha extendido sobre la zona lacustre que fue desecada artificialmente, lo que aunado a la sobreexplotación de los acuíferos provocan múltiples problemas con el suelo: zona con fallas y fracturas que son susceptibles de inundaciones y hundimientos» (Encinas, 2015:47).

\section{Metodología}

El trabajo utilizó el método deductivo, para alcanzar el conocimiento de lo general desde lo particular, comparando y analizando los datos cuantitativos disponibles y realizando análisis cualitativo de cada uno de los temas de la investigación, con apoyo y seguimiento del objetivo planteado. Por lo que se refiere a las técnicas de investigación, se realizó una revisión de información documental escasamente conocida e información electrónica de la temática referida; entrevistas a conocedores del tema y del proyecto; tal fue el caso de la entrevista al ex director de Desarrollo Urbano del municipio de Texcoco, Ing. Alfredo Ramírez López en el año 2017 y a Gabriel Quadri, candidato a la Presidencia de la República en el 2012 y en el 2016 Diputado Constituyente en la Ciudad de México. La entrevista con Quadri se realizó en el marco de los Foros del Nuevo Aeropuerto Internacional de la Ciudad de México ${ }^{5}$ y al Ing. Ramírez López en instalaciones del H. Ayuntamiento de Texcoco en el mes de enero de 2017 .

5. Foros organizados por el Instituto Mexicano de la Competitividad (IMCO) El Centro Mexicano de Derecho Ambiental, A.C (Cemda), el Centro de Transporte Sustentable (CTS Embarq), y la Agencia de EE.UU. para el Desarrollo Internacional (Usaid), en los meses de octubre, noviembre y diciembre del 2014. Asimismo, se efectuaron ocho visitas de campo en el municipio de Texcoco en octubre y noviembre del 2016, y enero 2017 . 
El área de estudio para la realización de la investigación comprende el municipio de Texcoco, se localiza en la parte central de la zona oriente del Estado de México y al nororiente de la Ciudad de México (Mapa 1).

\begin{tabular}{|l|l|}
\hline MAPA 1 & Mapa de ubicación de Texcoco \\
\hline
\end{tabular}
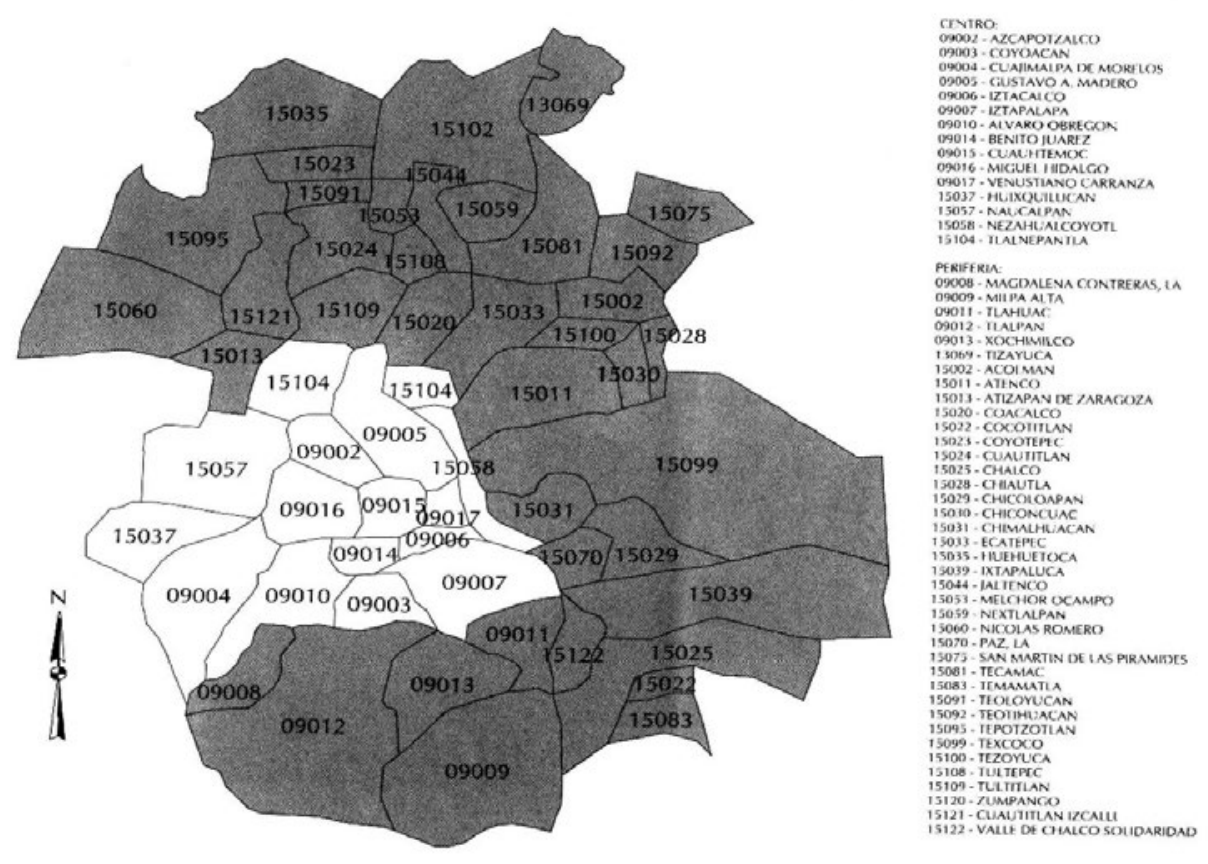

Fuente: Elaboración propia con información de Inegi, 2000 y 2010.

El anterior mapa permite observar con detalle donde se ubica Texcoco (15099) y los municipios vecinos. Llama la atención que dicho municipio es el más grande territorialmente de la Zona Metropolitana de la Ciudad de México; también se observa la ubicación de Atenco (15011) los dos que se ubican con mayor impacto por el aeropuerto, así como los otros municipios citados y las delegaciones de la Ciudad de México. Más adelante se muestra la ubicación del NAICM. 


\section{El aeropuerto en el ex Lago de Texcoco}

La zona lacustre de lo que fuera el Lago de Texcoco sigue siendo una zona de reserva muy importante para la zona metropolitana del país; existen procesos del ciclo hídrico como la precipitación, la evapotranspiración, el escurrimiento artificial y natural, y la recarga de los acuíferos, que son importantes para mantener el equilibrio ambiental y la sustentabilidad de la región. Es de señalar que el terreno donde se construye el NAICM comprende las siguientes características:

EL NAICM será construido en un terreno de aproximadamente 4.431 hectáreas ubicadas al este de la ciudad, y a 14 kilómetros al este del AICM existente. El sitio está limitado al norte por el Depósito de Evaporación Solar «El Caracol», al sur por la carretera Peñón-Texcoco, al este por tierras de cultivo, y al oeste por áreas urbanizadas de las delegaciones Gustavo A. Madero y Venustiano Carranza, así como el municipio de Ecatepec de Morelos (SCT, 2015a).

\section{MAPA 2 Ubicación del nuevo Aeropuerto Internacional de la Ciudad de México}

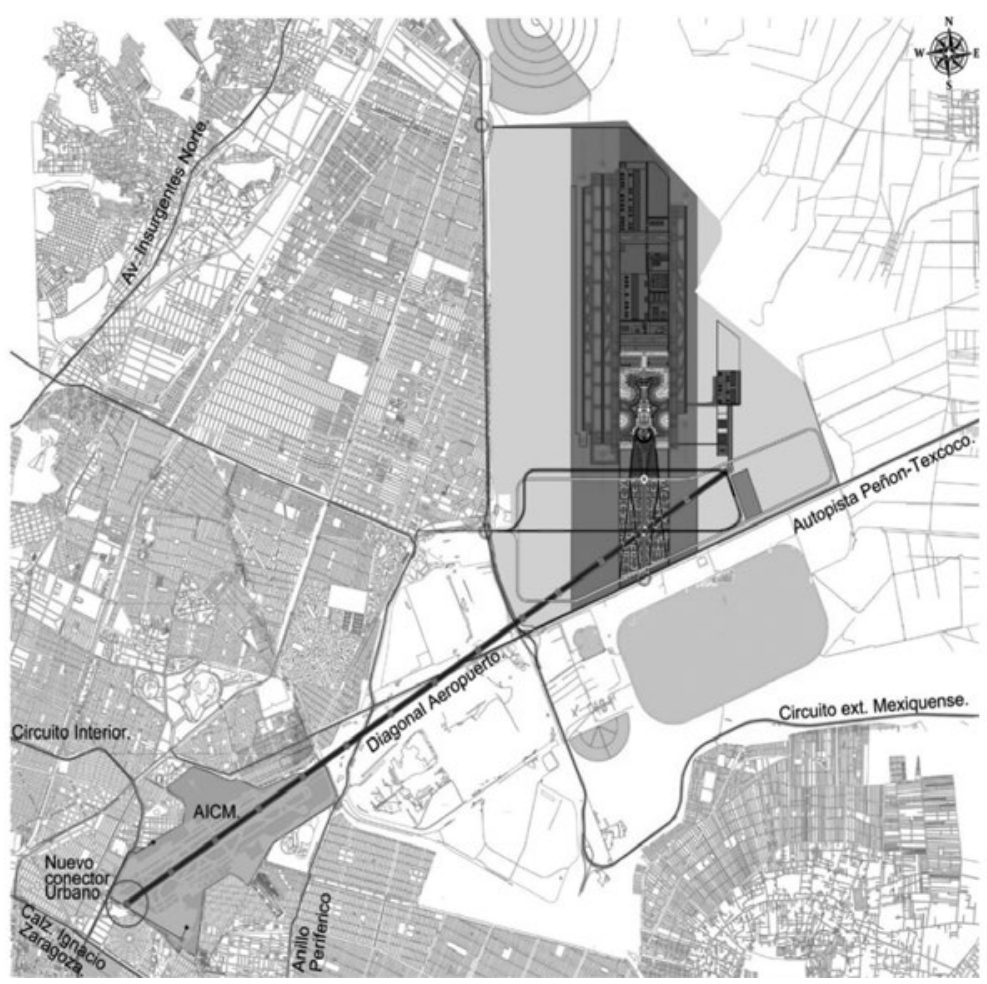

Fuente: Tomado de Serrano Arquitectos, 2017. 
El NAICM se construye en la zona hidrológica del Valle de México, en específico en la subregión Texcoco, que se encuentra clasificada como sobreexplotada en su condición geohidrológica en los acuíferos de la región. También se encuentra sobreexplotado el acuífero Chalco-Amecameca, Cuautitlán-Pachuca y la Ciudad de México y su Zona Metropolitana (Conagua; 2004).

El siguiente cuadro ilustra la condición del acuífero de la región oriente del Estado de México, misma que comprende 37 municipios del oriente del Estado de México y las 16 Delegaciones de la Ciudad de México, en donde se estima habitan más de 14 millones de personas (Inegi, 2010).

\begin{tabular}{|l|l|}
\hline CUADRO 1 & $\begin{array}{l}\text { Situación de acuíferos de la región XIII. } \\
\text { (hm3/año). Subregión Valle de México }\end{array}$ \\
\hline
\end{tabular}

\begin{tabular}{|c|c|c|c|c|c|}
\hline $\begin{array}{l}\text { Unidad hidrogeológica } \\
\text { (acuífero) }\end{array}$ & Recarga & $\begin{array}{c}\text { Descarga } \\
\text { natural com- } \\
\text { prometida }\end{array}$ & $\left|\begin{array}{c}\text { Volumen } \\
\text { concecionado } \\
\text { de agua }\end{array}\right|$ & $\left|\begin{array}{c}\text { Disponibili- } \\
\text { dad media de } \\
\text { agua subte- } \\
\text { rránea }\end{array}\right|$ & Déficit \\
\hline $\begin{array}{c}\text { Zona Metropolitana } \\
\text { de la Ciudad de } \\
\text { México }\end{array}$ & 279,0 & $\mathrm{o}, \mathrm{O}$ & 1248,6 & $\mathrm{o}, \mathrm{o}$ & $-969,6$ \\
\hline Texcoco & 48,6 & $\mathrm{O}, \mathrm{O}$ & 92,5 & $\mathrm{o}, \mathrm{o}$ & 43,9 \\
\hline Chalco-Amecameca & 74,0 & $\mathrm{O}, \mathrm{O}$ & 90,4 & $\mathrm{o}, \mathrm{o}$ & $-16,4$ \\
\hline Cuautitlán-Texcoco & 202,9 & $\mathrm{O}, \mathrm{O}$ & 17,9 & 1,3 & $\mathrm{O}, \mathrm{O}$ \\
\hline
\end{tabular}

Fuente: Elaboración propia con datos de Estadísticas del agua 2004 aguas del Valle de México y Sistema Cutzamala, Conagua/Semarnat, 2004.

Es de mencionar que la subregión XIII en el Valle de México también está integrada por Tecocomulco, Apan y Soltepec que de manera física se ubican más alejados del NAICM y del Lago de Texcoco.

El ámbito territorial de la región XIII de Aguas del Valle de México y Sistema Cutzamala se ubica en la cuenca alta del Río Pánuco; está formada por dos subcuencas: la del Valle de México y la del Río Tula. Atendiendo al parteaguas de estas subcuentas, la superficie física de la cuenca es del orden $16.392 \mathrm{~km} 2$, de los cuales $60 \%$ son del Valle de México y $40 \%$ corresponden al territorio del Río Tula. De esta superficie, $40 \%$ corresponde al territorio del Estado de México con 59 municipios; 48 al Estado de Hidalgo con 39 municipios; 9 \% de la Ciudad de México con sus 16 
Delegaciones y sólo el tres por ciento de la superficie al estado de Tlaxcala con cuatro municipios. Su clima se clasifica como seco templado con temperatura media anual de $11^{\circ} \mathrm{C}$ y con una precipitación media anual de 630 milímetros (Conagua, 2003:11).

En lo que queda del vaso del Lago cuenta con lagos y lagunas que ayudan a mantener un equilibrio ecológico y ambiental en la zona y su efecto se siente en toda la región y los municipios colindantes, donde actualmente se construye el nuevo aeropuerto internacional de la Ciudad de México. El siguiente cuadro (2) muestra los cuerpos de agua que existen en la zona federal del vaso del Lago de Texcoco, municipio de Texcoco.

\begin{tabular}{|c|c|c|c|c|}
\hline CUADRO 2 & \multicolumn{4}{|c|}{ Principales lagos y lagunas (medias históricas) } \\
\hline Nombre & $\begin{array}{l}\text { Área de la Cuenca } \\
\text { (ha) }\end{array}$ & $\begin{array}{c}\text { Volumen medio } \\
\text { almacenado } \\
\left(\mathrm{hm}^{3}\right)\end{array}$ & $\begin{array}{c}\text { Localización } \\
\text { (municipio) }\end{array}$ & $\mid \begin{array}{c}\text { Entidad Federativa } \\
\text { o estado }\end{array}$ \\
\hline $\begin{array}{l}\text { Lago Dr. Nabor } \\
\text { Carrillo }\end{array}$ & 1000 & 36,00 & Texcoco & Estado de México \\
\hline $\begin{array}{c}\text { Laguna } \\
\text { Xalapango }\end{array}$ & 280 & 5,60 & Texcoco & Estado de México \\
\hline $\begin{array}{c}\text { Lago de Texcoco } \\
\text { Norte }\end{array}$ & 35 & 0,35 & Texcoco & Estado de México \\
\hline Lago recreativo & 25 & 0,37 & Texcoco & Estado de México \\
\hline
\end{tabular}

Fuente: Elaboración propia con datos de Estadísticas del agua 2004 aguas del Valle de México y Sistema Cutzamala, Conagua/Semarnat, 2004. pp. 26.

Es de resaltar que en territorio texcocano se ubica el cuerpo de agua más importante de la zona metropolitana de la Ciudad de México y del área conurbada, el lago «Nabor Carrillo», que se observa desde tierras altas de Texcoco, en específico en la montaña texcocana y en las zonas altas cercanas a la Ciudad de México, tiene extensión de 1.000 hectáreas. «Dicho cuerpo de agua tiene una capacidad de 36 millones de metros cúbicos de agua, además tiene bordo perimetral de 12 kilómetros» (Conagua, 2004: 26), y se ubica al sur del NAICM a no más de 2 kilómetros de distancia. Este lago artificial y las lagunas que existen en la zona federal del ex Lago de Texcoco son parte de un complejo de pequeñas lagunas-facultativas de recirculación-para el tratamiento de aguas residuales a través de procesos químico-biológicos así como en beneficios agrícolas, de industria y otros servicios de municipios cercanos como 
Texcoco, Nezahualcóyotl, Ecatepec y Chimalhuacán, mismos que tienen colindancia con el NAICM. «El ex Lago de Texcoco es alimentado por los ríos Churubusco, La Compañía, Los Remedios y los ríos de Oriente que incluyen las siguientes corrientes; San Juan Teotihuacán, Papalotla, Xalapango, Coxcacoaco, Texcoco, San Bernardino, Chapingo, Coatepec, y Santa Mónica» (Conagua; 2007: 53).

El proyecto del Lago de Texcoco lleva más de 40 años de trabajar en la recuperación de suelos, de tratar de revertir la tendencia del deterioro causado por el hombre y el tipo de desarrollo en la región y en la metrópoli más grande de México y Latinoamérica.

En el Plano de Infraestructura Hidráulica del Proyecto del Lago de Texcoco, autorizado por la Conagua y la Secretaría del Medio Ambiente y Recursos Naturales (Semarnat), se considera que donde se construye el NAICM es una zona de reserva ecológica; además se ubica la Laguna Casa Colorada, Dren Texcoco Norte, donde se realizan obras para acceso al nuevo aeropuerto. Lo anterior no ha sido modificado en documento impreso o electrónico (Conagua, 2007).

Las acciones de recuperación de la zona de Texcoco, realizadas a lo largo de las últimas tres décadas permitieron que aumentara la presencia de aves migratorias y se establecieran poblaciones residentes, lo que originó la necesidad de conservar los beneficios ambientales que esa área representa. Por ello, a lo largo de cinco años se realizaron estudios con los siguientes objetivos: contar con información confiable respecto al número y diversidad de aves acuáticas migratorias y residentes, a fin de establecer la importancia del vaso de Texcoco como zona de refugio; determinar el impacto que se tendría con la construcción del nuevo aeropuerto para la avifauna $\mathrm{y}$, en su caso, proponer medidas de mitigación o hábitat alternativos, y conocer en cabalidad el riesgo que pudiera significar la presencia de aves para la navegación aérea (Aeropuertos y Servicios Auxiliares ASA, 2003: 235-236)

En entrevista realizada al Ing. Alfredo Ramírez, ${ }^{6}$ funcionario municipal de Texcoco en el periodo 2016-2018, explicó lo relativo al NAICM en el Lago de Texcoco y en el papel que desempeña el gobierno local en el municipio del mismo nombre. Así lo explicó el Ing. Ramírez en las oficinas municipales de Texcoco:

6. El Ing. Alfredo Ramírez López fue presidente municipal sustituto del Lic. Horacio Duarte Olivares, durante el periodo 2000-2003; luego fue designado por el cabildo municipal y ratificado por el Congreso Estatal como presidente interino del 1 de marzo al 18 de agosto de 2003, fecha en que entregó el $\mathrm{H}$. Ayuntamiento al médico Higinio Martínez Miranda, presidente electo para el periodo de 2003-2006. Martínez Miranda repite como presidente municipal para el periodo 2016-2018, y el Ing. Ramírez es designado en 2016 como Director General de Desarrollo Urbano del H. Ayuntamiento de Texcoco. El citado ingeniero Ramírez es Ingeniero Civil por la Universidad Nacional Autónoma de México (UNAM), trabajó en la Universidad Autónoma Chapingo, en el área de Irrigación, y ha realizado diversos estudios acerca del acuífero de Texcoco y la región. En la fecha de la entrevista se desempeñaba como director de 


\section{¿Cómo ha sido el cambio de uso de suelo en terrenos del Lago de Texcoco?}

El uso de suelo no ha cambiado de por sí, siempre ha sido el mismo uso, de una parte del ex vaso del lago de Texcoco, es agropecuario y de reserva ecológica, no ha cambiado. Hasta las modificaciones que estamos preparando con este nuevo Plan de Desarrollo Urbano. En los terrenos cercanos se está proponiendo un uso de transferencia tecnológico y agroindustrial, cercano al nuevo aeropuerto.

\section{¿Pero actualmente cómo está el uso de suelo?}

Lo teníamos como agropecuario, es una reserva ecológica, pero desde el punto de vista del catastro lo tenemos como «especial», o sea en las áreas homogéneas que tenemos clasificado en Catastro, toda la parte del aeropuerto está como «especial 3» y en el uso de suelo en desarrollo urbano está como reserva ecológica, porque va más hacia Atenco... obviamente esta es una parte agropecuaria y otra de reserva ecológica. El área del aeropuerto en la porción de Texcoco y Atenco está en área homogénea «especial 3», en el caso específico de Texcoco. Con respecto a desarrollo urbano en reserva ecológica y una pequeña porción en uso agropecuario, de mala calidad, tú sabes, el «barco», y todo eso, los ejidos de Tocuila, siembran, pero de mala calidad.

\section{¿Existe antecedente o alguna petición o antecedente del Grupo Aeropor- tuario de la Ciudad de México o de la SCT para el cambio de uso de suelo?}

Ninguna, cuando fui director de desarrollo urbano, lo que nos solicitaron los servicios aeroportuarios de la Ciudad de México fue el alineamiento y el número oficial, y eso sí les fue otorgado. No nos hicieron petición de cambio de uso de suelo. Y no los hicieron porque Desarrollo Urbano municipal no es la competencia para dar el cambio de uso de suelo; primero se solicita en la delegación de desarrollo urbano del Gobierno del Estado de México, y luego en la delegación Texcoco, ellos les dan el uso de suelo. El que tenemos es Plan de Desarrollo vigente. Pero si lo solicitan tendrían que hacerlo a través del Ayuntamiento de Texcoco, con lo que se nombra Coplademun, es una Comisión de Planeación de Desarrollo Municipal, donde se reúnen varias autoridades y se hace la petición, y ahí se aprueba el cambio de uso de suelo que pudiera haberse pedido para el uso aeroportuario.

\section{¿El NAICM en el ex Lago?}

Primero, es un proyecto necesario, sabemos de la gran polémica si se construía en terrenos cercanos a Texcoco, en Atenco en su momento o en Tizayuca, Hidalgo. Los estudios técnicos realizados que tuve la oportunidad de conocer cuando trabajé para el gobierno de la Ciudad de México, todos los estudios, se inclinaban en el antiguo ex

Catastro Municipal, y mencionó que en un futuro seguramente se encargará de la Escuela Universitaria de Ingeniería Civil de Texcoco, A.C. La entrevista fue realizada el 26 de enero de 2017 en las oficinas de Catastro del H. Ayuntamiento de Texcoco 2016-2018. 
Lago de Texcoco, y en terrenos del municipio de Atenco, y hoy en día una tercera parte del polígono del aeropuerto está en Texcoco. Desde el punto de vista estratégico, desde el punto de vista de la problemática del agua, tengo entendido que el abastecimiento del agua para el aeropuerto y los servicios será dada con agua residual; es decir, tratarán todas las aguas residuales negras y pluviales que lleguen contaminadas y no contaminadas y serán objeto de tratamiento para satisfacer todas las necesidades del aeropuerto.

El impacto que va a provocar construir el aeropuerto con la explosión demográfica es obvio; ya hemos hecho cálculos en las proyecciones de la población; por ejemplo, para el año 2035 es de casi quinientas mil personas; cómo vamos a abastecer a esta gente de agua, con un crecimiento natural normal y de acuerdo a las predicciones que hemos hecho, aparentemente nos estaría haciendo falta el recurso agua, con aeropuerto y sin aeropuerto, porque ya dije que el aeropuerto se abastecerá con aguas tratadas. Sin embargo, ya que he estudiado el acuífero Texcoco, el sistema hidrológico dentro de lo que es Texcoco y el Valle, desde el Río Coatepec que está en los límites de Chicoloapan, hasta el Río Xalapango, hemos hecho diversos estudios con la Universidad Autónoma Chapingo sobre la disponibilidad de agua subterránea y efectivamente el acuífero se encuentra sobreexplotado, no como se anda diciendo por ahí, que tenemos una sobreexplotación del 200 por ciento, eso es mentira porque con los estudios que hemos hecho no llegamos a tener un grado de explotación del so por ciento. Probablemente se alcanzó esta sobreexplotación cuando Texcoco era una cuenca lechera, y el principal uso de agua superficial era destinado a la agricultura y la ganadería. Ahí sí se consumían grandes cantidades de agua. Con el crecimiento urbano también ha crecido la demanda y de satisfacerla a través de agua subterránea, con los cálculos que hemos hecho con el nuevo Plan de Desarrollo Urbano, podemos seguir creciendo de manera ordenada; y eso de que se van a agotar los acuíferos no es correcto. El agotamiento de los acuíferos se va a dar en una reserva que tenemos almacenada, que de acuerdo a los estudios, si sabemos almacenarla y cuidarla correctamente tenemos para un buen número de años... esa es mi apreciación. Nosotros recibimos recarga vertical ascendente de acuíferos regionales, que el flujo subterráneo que viene muy a profundidad precisamente por el abatimiento de los niveles del acuífero, estamos recibiendo agua de estratos inferiores porque la lógica es que la recibiéramos de la lluvia. Nos apoyamos en estudios científicos del Instituto de Geología y de Geofísica de la UNAM, que han demostrado esos flujos regionales, con estudios científicos... se puede demostrar.

Lo anterior es expresión de un funcionario municipal que conoce la problemática del proyecto del aeropuerto en Texcoco; sin embargo, es una de las dimensiones que expresan un orden de gobierno, en este caso del ámbito local. La información de Conagua y SCT expresan el orden federal. Lo que se observa en el ámbito del gobierno estatal es la casi nula expresión respecto al proyecto del aeropuerto. A pesar de estar construyéndose en territorio mexiquense, la Constitución del Estado de México 
manifiesta soberanía y autonomía para decisiones del orden local. Las decisiones más importantes acerca del NAICM se han remitido al orden federal. Se sugiere la siguiente pregunta: ¿Cuáles son las obras más importantes que se construyen en la zona federal del ex lago de Texcoco? La SCT y el Grupo Aeroportuario de la Ciudad de México mencionan las siguientes:

La nueva terminal del NAICM Edificio Terminal tendrá 743 mil 911 metros cuadrados, sobre una losa de cimentación de 315.193 metros cuadrados que descansará sobre un total de 5.173 pilotes y en su fase inicial podrá trasladar 68 millones de pasajeros al año (en promedio 186 mil diarios), con un crecimiento previsto para llegar a un total de 125 millones de pasajeros. Podrá atender hasta 855 mil vuelos al año para llegar hasta 1 millón en su máxima etapa de desarrollo (SCT; 2017).

Durante 2017 están la construcción del entronque Peñón-Texcoco y Los Reyes-Texcoco; el Centro Multimodal de Transporte; Pista 6 y Calles de Rodaje; Red de Distribución Eléctrica de Medio Voltaje, Subestaciones y Cableado Estructurado; Plataformas (Terminal de Pasajeros, Terminal de Carga y Áreas de Mantenimiento), Túneles de Servicio y Pasos a Desnivel para Equipo de Apoyo Terrestre. También se laborará en el entronque Ingreso Terminal Aérea desde Autopista Peñón-Texcoco; el Entronque Zona Gubernamental-Pirámides en Campus Sureste; Sistemas de Ayudas a la Navegación; Sistema de Ayudas Visuales; Terminal y Red de Distribución de Combustible, y Centro de Control Aéreo. Otros trabajos incluyen Nivelación y Limpieza, Distribución de Servicios, la Red de Distribución de Energía, Agua y Drenaje; Plantas Centrales de Servicios-Este y Oeste; Red de Distribución de Servicios, Alcantarillado Pluvial, Drenaje Sanitario y Plantas de Bombeo del Aeropuerto/Caminos y Servicios del Campus Medio; Integrador Maestro de Sistemas y Sistema General de Seguridad; Planta Central de Servicios del Campus Sureste; Edificios de Mantenimiento del Campus Medio; Terminal de Combustibles del Campus Sureste; Vialidad Elevada de Acceso al Edificio Terminal y el Túnel y Estructura de Estación del Metro, dijo la dependencia en un comunicado (Reyna, 2017).

Las anteriores son las principales obras registradas para el año 2017, también se explica que será en el mes de octubre del 2020 cuando darán inicio las operaciones de la primera etapa del NAICM, y la inflación y la devaluación del peso mexicano serán determinantes del costo total del nuevo aeropuerto, originalmente programado en 169 mil millones de pesos (Mayor inflación subirá el costo del NAICM, 2017). Sin embargo, existe nueva información que considera que de acuerdo con las cifras que la SCT y el Grupo Aeroportuario de la Ciudad de México (GACM) han actualizado, el valor total del NAICM ya ronda en los 186 mil millones de pesos, frente a los 169 mil millones de pesos que era su valor inicial; es decir, el costo creció $10 \%$ más, lo que significa 17 mil millones de pesos más. Otra cifra, calculada por partidos políticos 
como Movimiento Regeneración Nacional (Morena), coloca al NAICM con un valor aproximado de 200 mil millones de pesos (Cuánto nos costrá..., 2017).

También se destaca que entre otras obras que se realizan se encuentra la construcción de la Barda Perimetral de 33 kilómetros bajo supervisión del ejército mexicano; contribuirá a crear entre 30 y 40 mil empleos directos durante 2016-2017 y hasta 160 mil directos e indirectos durante todo el periodo de construcción. Una vez que entre en operación a finales de 2020, el nuevo aeropuerto generará 450 mil trabajos y será el empleador número uno en la zona metropolitana. Tendrá una capacidad instalada para 50 millones de pasajeros al año y alrededor de 550 mil operaciones. En su etapa máxima de desarrollo, con seis pistas en operación simultánea, podrá atender hasta 125 millones de pasajeros anualmente; más de un millón de aviones cada año tendrán la posibilidad de aterrizar y despegar (SCT, 2015b). Según Aeropuertos y Servicios Auxiliares (ASA) en el año 2002 trabajaban más de mil empleados en el aeropuerto de la Ciudad de México (ASA, 2003: 230); lo cual contrasta con la propuesta del NAICM, está por conocerse si efectivamente se aumentará de manera significativa el empleo en las instalaciones del nuevo aeropuerto; se desconoce el número de empleos indirectos en torno al actual aeropuerto en la Ciudad de México, no existe estadística oficial al respecto. En términos generales, dice el gobierno federal que será el mayor empleador que exista para la zona metropolitana de la Ciudad de México, según el secretario de la SCT serían más de 500 mil empleos, desde su diseño hasta su operación (González, 2017).

Es de señalar que la extensión territorial para la construcción del NAICM es de 4.435 hectáreas en el vaso del Lago de Texcoco, y no todo será construido en dicha extensión, pero sí es seis veces más grande que el actual aeropuerto de la Ciudad de México. En el año 2015 existió licitación para nivelar terreno de más de 4.350 hectáreas; ello conducirá, posteriormente, a la nivelación del terreno para construir el edificio y tender las pistas de despegue y aterrizaje (SCT, 2015a). Se estima que el NAICM se construirá en una extensión de más de 1.500 hectáreas, es decir, el doble del actual aeropuerto capitalino.

Por otro lado, el Plan de Desarrollo Urbano vigente de Texcoco (2004) tiene más de una década, al igual que el Plan de Desarrollo Urbano (2005) de la entidad mexiquense; esto permite identificar el retraso de dichos documentos que son norma y guía en el ordenamiento urbano-territorial-ambiental en el ámbito local, toda vez que la magnitud e importancia de las acciones locales quedan limitadas y rebasadas por las acciones presentes. Tal es el caso de la instalación del NAICM en territorio mexiquense y texcocano, sin que exista congruencia con el proyecto de desarrollo urbano para el municipio y la entidad más poblada del país y la de mayor interacción social, ambiental y económica. 
En el texto del Plan de Desarrollo Urbano de Texcoco (2004) dice:

Por otro lado, existen dentro del municipio 91,36 km2 que representan el 21,82\% de su superficie que son susceptibles de inundaciones; estas áreas se concentran hacia el vaso del Lago de Texcoco (VELT). Así mismo, existen algunos encharcamientos en la Cabecera Municipal que generan conflictos viales en época de lluvias. La más grave fuente de contaminación en el municipio de Texcoco lo constituyen la gran concentración de basura, así como la descarga de las aguas residuales y drenajes domésticos de las localidades del municipio a los ríos y canales que cruzan de este a poniente, y que desembocan en el Vaso de Texcoco (Gobierno del Estado de México, 2004: 17-38).

Es de señalar que la extensión territorial no ha sido modificada, a pesar de estar construyéndose el NAICM en parte del territorio texcocano. La extensión de Texcoco de manera oficial es de 41.869 hectáreas, se encuentra organizado políticamente y administrativamente por la cabecera municipal denominada Texcoco de Mora y 56 localidades, entre las que destacan las más grandes por el número de pobladores: San Miguel Coatlinchan, y Santiago Cuautlalpan ubicados al sur del municipio, y la cabecera municipal que supera los 100 mil habitantes (Plan de Desarrollo Urbano, 2004). Las comunidades más cercanas al NAICM en Texcoco son Colonia Guadalupe Victoria, Santa Cruz de Abajo, San Felipe, San Miguel Tocuila, y La Magdalena Panoaya, son pueblos conocidos como de la ribera texcocana desde hace más de cuatro siglos.

El ex Lago de Texcoco y lo que queda de su terreno original ha servido para reducir el peligro de las inundaciones en grandes áreas de la zona urbana y áreas productivas, con lo que ha ayudado a mantener el equilibrio ecológico. Es una zona de mitigación y rescate ecológico que está rodeada por la zona metropolitana en su parte oriente y nororiente. La pregunta que surge: ¿La zona del NAICM podrá seguir regulando los escurrimientos superficiales, ya que esta es una de las funciones ecológicas de los lagos artificiales que existen en la zona? Es de señalar que parte de las funciones del ex vaso del Lago de Texcoco es ser un regulador de los escurrimientos artificiales. Por otra parte, la construcción del nuevo aeropuerto en el sitio propuesto representa un elemento que incidía en la actividad hidráulica reguladora que se lleva a cabo en esa zona, por lo que era necesario reemplazar las áreas de regulación con otras nuevas para evitar descargas importantes al Dren General del Valle que pudiera comprometer su función primordial de conducir las avenidas que descargan los ríos Churubusco y la Compañía hacia fuera del Valle de México, vía el Gran Canal de Desagüe y los túneles de Tequisquiac. Al proyectar las obras para la conducción, almacenamiento temporal y descarga de los escurrimientos de la vertiente oriental del Valle, también era necesario considerar el previsible crecimiento de la zona urbana, la cual continuará su desarrollo y provocaría un aumento notable 
en los volúmenes de escurrimiento durante tormentas, debido principalmente a la pavimentación, la cual también contribuiría a reducir los tiempos de concentración (ASA, 2003: 298). Según la SCT, el NAICM utilizará agua captada por las mismas lluvias: el 100\% del agua residual será tratada y el consumo será $79 \%$ menor a la del aeropuerto actual (SCT, 2017).

Lo anterior permite reflexión y análisis para valorar las externalidades ambientales poco valoradas en el contexto de las grandes obras urbanas, que por un lado traen problemas ambientales y ecológicos escasamente valorados, y por otro son obras de infraestructura de gran trascendencia para la competitividad internacional de un país y una región.

Nadal (2007) considera de la mayor importancia la relación que guarda el tema económico y el tema ambiental y comenta lo siguiente:

Existe una fuerte controversia sobre el impacto económico sobre el medio ambiente y sobre el desarrollo sustentable. Por un lado están los que consideran que el crecimiento del ingreso per cápita es una solución a los problemas del deterioro ambiental y el desgaste de la base de recursos naturales. Por otro lado encontramos aquellos autores que sostienen que el crecimiento y, en especial, las modalidades de la globalización de mercados bajo un esquema neoliberal, representan una seria amenaza para el medio ambiente e imposibilitan el desarrollo sustentable (Nadal, 2007: 17).

\section{Conclusión}

La construcción de la más importante obra urbana que ha existido en Texcoco se realiza en el llamado ex Lago de Texcoco, en la «Zona Federal» de gran tradición histórica para los mexicas y los texcocanos -pueblos milenarios- que ha existido antes de la conquista española y reconocidas sus obras arquitectónicas y de ingeniería hidráulica en el transcurso de la historia. El NAICM se construye en una zona de reserva ecológica, en lo que eran terrenos que tenían vocación de zona sujeta a inundación, de recuperación de suelos, de proyectos ecológicos por parte de la Comisión Lago de Texcoco, y de Conagua. Ahora son utilizados llenándoles de materiales de construcción, como arena, grava, tezontle, plásticos, cemento, hierro y diversos materiales que se utilizan en las pistas, torres de control y acceso al aeropuerto en 1.50o hectáreas de un total de 4.435 del citado megaproyecto urbano más importante que ha existido en la ZMCM en las últimas cuatro décadas. De manera cotidiana entran y salen del ex lago de Texcoco más de 1.400 vehículos de carga con materiales que transforman el espacio territorial, antes de vocación ecológica en territorio texcocano. Es una realidad el impacto ambiental que generan los vehículos con la 
polución, contaminación de aire, tierra y agua que significa esta megaobra urbana. Los problemas ambientales en el Lago de Texcoco seguramente tendrán efecto en los pobladores de Texcoco y la región. La problemática del agua, su calidad, el aire y el efecto de cambio de usos de suelo se ha tratado de reducir a una cuestión administrativa, de soluciones técnicas poco sustentadas en el análisis socioambiental de las localidades y de las regiones. Son notorias las contradicciones en el tema del aeropuerto sobre el Lago de Texcoco, donde literalmente se desechó parte importante del proyecto ecológico-ambiental de un organismo público descentralizado del gobierno federal que encabeza Conagua y los millones de pesos que se invirtieron en dicho proyecto por más de tres décadas. En la práctica es utilizado por la SCT y el Grupo Aeroportuario de la Ciudad de México para la construcción del NAICM.

También se reconoce la importancia y trascendencia de este megaproyecto urbano que permitirá atender la creciente demanda de movilidad de personas y mercancías, el transporte aéreo es una opción en un mundo cada día más globalizado. Desde finales del siglo pasado, en la década de los 9o, empezaron los estudios técnicos y financieros para analizar la posibilidad de construir un nuevo aeropuerto; y luego, en el inicio del siglo XXI, se observó y analizó por el gobierno federal las opciones de Tizayuca y Texcoco. Para atender la demanda de largo plazo (más de 50 años) se propuso que el aeropuerto tuviera tres grandes pistas paralelas que permitieran operaciones simultáneas independientes y un terreno amplio de más de 4 mil hectáreas, ya que el actual era pequeño para las operaciones crecientes. Otro de los elementos considerados fue el centro generador de demanda y las vías de comunicación y acceso; se observó la opción Tizayuca, en el Estado de Hidalgo, y Texcoco, en el Estado de México. También se estudió la posibilidad de los rellenos sanitarios en el llamado bordo poniente, que en realidad se ubica en oriente a menos de $3 \mathrm{~km}$ de donde se ubica la construcción del NAICM; esta última opción era muy complicada desde la dimensión técnica y su espacio o superficie era menor a la considerada.

La idea de instalar el NAICM en terreno del ex vaso de Texcoco conlleva que aún están por conocerse sus implicaciones ambientales, territoriales y sociales. Se conocerá si realmente las justificaciones técnicas y económicas fueron las adecuadas; el presente artículo contribuye al análisis, al estudio y a las adecuadas decisiones del proyecto y su impacto en la condición ambiental, ecológica, urbana y social. La coherencia con el entorno metropolitano es una de las dimensiones escasamente estudiada en los trabajos académicos para la zona metropolitana y megalópolis más importante del país.

Se pretende conocer si realmente se dinamiza la parte oriente del Estado de México, la cual presenta concentración urbana significativa; si existirá mejora en lo 
económico y social, y si el aeropuerto permite compatibilizar las dimensiones de la sustentabilidad, de espacio territorial en una zona de reserva ecológica y mitigación donde el recurso agua, la avifauna y el cuerpo de agua más importante-el Lago Nabor Carrillo-, las lagunas recreativas y facultativas y las nuevas zonas inundables estan presentes. Si es compatible operar el aeropuerto más importante de Latinoamérica con un proyecto ecológico, urbano e hidrológico de la mayor trascendencia, por las implicaciones sociales, económicas, culturales y político-administrativas para la región y el país, tenuendo en cuenta que el NAICM se ubica en otra entidad distintaal estado de México, en particular, el municipio de Texcoco de Mora.

La construcción del NAICM tiene un impacto social, ambiental y urbano poco valorado en los distintos órdenes de gobierno federal, estatal o municipal. El papel de los gobiernos locales y sus facultades establecidas en la Constitución Mexicana y en el artículo 115 son relevantes y adquieren otra dimensión cuando municipios como Texcoco son parte de la integración metropolitana más importante que existe en México. En este punto llama la atención lo expresado por el gobierno local de Texcoco, donde el funcionario entrevistado deja entrever la confusión entre zona de reserva ecológica y uso de suelo agrícola, y el problema está en gran medida en lo expresado en el Plan de Desarrollo Urbano de Texcoco (2004) y lo Conagua considera reserva ecológica; y peor aún, la falta de congruencia con los planes estatales y regionales para esta zona, que no estaba considerada para aeropuerto en sus documentos oficiales. La relación que se mantiene con la megalópolis del país también le da otra configuración; además, refleja la complejidad que se tiene con los distintos órdenes de gobierno en lo relativo al uso de suelo y al cambio al construirse el megaproyecto urbano más importante de México en la zona lacustre llamada Lago de Texcoco.

El lecho lacustre del ex Lago de Texcoco se fue con el tiempo desertificando, generando presión urbana por municipios como Chimalhuacán y Ecatepec, también la zona quedó expuesta a la modificación del ciclo hídrico como fue la precipitación, el escurrimiento natural y la recarga de acuíferos; era una zona más fría que la Ciudad de México o la cabecera municipal de Texcoco, sus más de 12 mil hectáreas quedarán reducidas con la construcción del nuevo aeropuerto que ocupará más de 4 mil hectáreas del polígono para dicha obra; siendo más de 1.500 destinadas a la construcción del puerto aéreo. También se debe pensar en la importancia que adquiere la zona de mitigación y rescate ecológico, no solo para Texcoco y la ZMCM, sino para todo el Valle de México y el país, pues el proyecto de la Comisión del Lago de Texcoco realizó trabajos importantes para la sustentabilidad de la región. Asimismo, falta conocer cuántas hectáreas más serán adquiridas por el gobierno federal a los ejidatarios de Texcoco y Atenco, así como conocer el dato exacto de predios de 
propiedad privada adquiridos para distintas obras hidrológicas y de mitigación que beneficien a la Zona Metropolitana más grande del país.

Es indudable que construir el aeropuerto internacional de la Ciudad de México en territorio mexiquense adquiere nuevo significado, en virtud de la nueva estructura urbana que se generará en otra entidad, el Estado de México, y que no será la Ciudad de México la sede del más importante aeropuerto de México y seguramente de Latinoamérica, pero tendrá efecto en una nueva estructura económica-productiva-ambiental, pues existirán cambios en la propiedad privada, en la ejidal y la comunal en Texcoco y municipios colindantes con el citado aeropuerto, toda vez que este se construye en un espacio territorial bajo resguardo de una dependencia descentralizada del gobierno federal como lo es Conagua, y que dentro de sus tareas más importantes tiene como misión velar por el cuidado del agua, en este caso, el último reducto del Lago de Texcoco. Además, se verá reducida en tamaño territorial a pesar de que dicha dependencia compró predios a ejidatarios del municipio de Texcoco y Atenco.

Lo anterior da cuenta de lo complejo e importante que se ha convertido el NAICM para la infraestructura, la competitividad y movilidad de personas y mercancías en el mundo globalizado. Además, es tema que relaciona lo urbano, lo territorial, el uso de suelo, las políticas públicas y las relaciones entre los distintos órdenes de gobierno, donde la calidad de vida, el tipo de desarrollo para el municipio y la región serán de lo más relevante. Se sabe que en el pasado los conflictos sociales por el aeropuerto generaron movilizaciones políticas, sociales y culturales que a la fecha continúan. Es tema permanente para el debate y la discusión de las políticas públicas emprendidas por el gobierno federal y hasta ahora siguen siendo compromisos de instituciones públicas y privadas que muchas ocasiones no cumplen con lo ofrecido, pues dependen de las variables sociales y políticas en turno.

Lo que es una realidad es que los pobladores pocas veces participan o son tomados en cuenta en la decisión de estas grandes obras que generan por un lado beneficios económicos, y de infraestructura que permiten a un país, región y municipio integrarse a la competitividad en el orden mundial; pero que también son obras que expresan problemas ambientales, ecológicos, de seguridad social, de conflicto social, de ganancias económicas a unos cuantos, de corrupción e impunidad en la toma de decisiones, lo cual está mediatizado por intereses políticos y económicos que generan contradicciones entre lo social, lo ambiental y lo económico. 


\section{Referencias}

AEROPUERTOS Y SERVICIOS AUXILIARES - ASA. (2003). Historia de la construcción, operación y administración aeroportuaria en México, México: ASA/IPN

CONAGUA. (2003). Programa Hidráulico Regional 2002-2006. Región XIII Aguas del Valle de México y Sistema Cutzamala. México: Conagua-Semarnat.

CONAGUA. (2004). Estadísticas del Agua. México: Secretaría del Medio Ambiente y Recursos Naturales/Conagua.

CONAGUA. (2007). Proyecto Lago de Texcoco. México: Secretaría del Medio Ambiente y Recursos Naturales-Conagua.

CONAGUA. (2012). Libro Blanco Conagua-o7 Programa Parque Ecológico Lago de Texcoco (PELT). México: Secretaría del Medio Ambiente y Recursos Naturales.

CONAGUA. (2015) Proyecto Hidráulico del Lago de Texcoco. Recuperado de: https://mail.googlr. com/mail/u/o\#/planurbanotexcoco\%4ogmail.com/155551849906

CONEVAL. (2011). Índice de Pobreza en los municipios de México. Obtenido el 28 de enero de 2017 en: www.coneval.gob.mx/informes/Pobreza/.../Pobreza_municipios.pdf

CONAGUA. (2012). Informe de pobreza y evaluación en el Estado de México 2012. Obtenido el 20 de enero de 2018 en: https://www.coneval.org.mx/coordinacion/entidades/Documents/ Informes\%2ode\%2opobreza\%2Oy\%2oevaluaci\%C3\%B3n\%202010-2012_Documentos/ Informe\%2ode\%2opobreza\%2oy\%2oevaluaci\%C3\%B3n\%2O2O12_Estado\%2ode\%2oM\%C3\%A9xico.pdf

CONAGUA. (2016). Medición de la pobreza. Pobreza a nivel municipio 2010-2015. Recuperado de: http://www.coneval.org.mx/Medicion/Paginas/Pobreza-municipal.aspx

CONSTANTINO, R. (2007). Recursos naturales y sustentabilidad: una perspectiva institucional y de acción colectiva. En: José Luis Calva (Coord.). Sustentabilidad y desarrollo ambiental. (p. 57). México: Miguel Ángel Porrúa-UNAM.

¿CUÁNTO NOS COSTARÁ EL NAICM? Y DESPUÉS, CUANDO QUEDE, ¿CUÁNTO PAGARÁN LOS USUARIOS? NO SE SABE. (2017) sinembargo.mx Recuperado de: http://www.sinembargo. $\mathrm{mx} / \mathrm{O} 5-10-2017 / 3310272$

EIBENSCHUTZ. (2013). Una estrategia para el futuro de la metrópoli. En: Ramírez, B. y Pradilla, E. (comp.). Antologías. Teorías y Políticas Territoriales. México: UAM-X.

ENCINAS, A. (2015). El Nuevo Aeropuerto Internacional de la Ciudad de México. Política, Negociosy Poder. México: Senado de la República. 
GOBIERNO DEL ESTADO DE MÉXICO. (24 de febrero de 2004). Plan de Desarrollo Urbano de Texcoco. Gaceta de Gobierno, 17-38.

GONZÁLEZ, L. M. (2017). NAICM generará más empleo que nadie en A.L. Recuperado de: https://www.eleconomista.com.mx/empresas/NAICM-generara-mas-empleo-que-nadie-enAL-20170518-0065.html

INEGI (200o). X Censo de Población y Vivienda. México: Inegi.

CONAGUA. (2010). XI Censo de Población y Vivienda. Aguascalientes, México: Inegi.

IRACHETA, A. (2009). Políticas públicas para gobernar las metrópolis mexicanas, México: Miguel Ángel Porrúa.

MAYOR INFLACIÓN SUBIRÁ EL COSTO DEL NAICM. (2017). El Economista. Recuperado de: http://eleconomista.com.mx/industrias/2017/o2/24mayor-inflación-subira-costo-naicm

NADAL, A. (2007). Medio ambientey desarrollo sustentable en México. E, en: José Luis Calva (Coord.). Sustentabilidady desarrollo ambiental. (p.17). México: Miguel Ángel Porrúa-UNAM.

OCDE. (2015). Valle de México Síntesis de Estudio. Recuperado de: https://www.oecd.org/regional/ regional.../valle-de-mexico-highlights-spanish.pdf

ONU. (2014). World Urbanization Prospects, the 2014 Revision. Highlights. Recuperado de: https:// esa.un.org/unpd/wup/ publications/files/wup2014-highlights.Pdf

QUADRI, G. (2014). Entrevista 1 realizada acerca del NAICM en Texcoco al ex candidato a la Presidencia de la República Mexicana y Asambleísta de la Ciudad de México. Obtenida el 27 de Noviembre de 2014 en el 3 Foro Ciudadano para analizar el Proyecto del Nuevo Aeropuerto Internacional de la Ciudad de México, en el Hotel de la Ciudad de México, Colonia Centro, D.F. Instituto Mexicano para la Competitividad A.C. (Imco), CTSEMBARQ/México, Centro Mexicano de Derecho Ambiental (Cemda) y la Agencia de EE.UU para el Desarrollo Internacional (Usaid).

RAMÍREZ, A. (2017). Entrevista personal realizada el 26 de enero de 2017 en las oficinas de Catastro del H. Ayuntamiento de Texcoco 2016-2018.

REYNA, J. (2017). Trabajos del NAICM con avance del 92\% al concluir el actual gobierno: SCT. Recuperado de: http://www.jornada.unam.mx/ultimas/2017/02/o6/contratacion-de-trabajos-delnaicm-con-avance-de-92-al-concluir-gobierno-de-epn

RIVERO, M. Y MORENO, E. (2017). Marco institucional de la gestión metropolitana en México. En Moreno, R. et al. (Coord.). Administración, gestión y profesionalización en gobiernos locales. (p. 40). Ciudad de México: IPAS.

SECRETARÍA DE COMUNICACIONES Y TRANSPORTES, SCT. (2015a). Inicia la construcción del Nuevo Aeropuerto Internacional de la Ciudad México. Recuperado de: http://www.sct. 
gob.mx/despliega-noticias/article/inicia-la-construccion-del-nuevo-aeropuerto-internacional-de-la-ciudad-mexico/

SECRETARÍA DE COMUNICACIONES Y TRANSPORTES, SCT. (2015b). El Nuevo Aeropuerto Internacional de la Ciudad de México, ventana al desarrollo regional de los próximos 50 años. Recuperado de: http://www.sct.gob.mx/despliega-noticias/article/el-nuevo-aeropuerto-internacional-de-la-ciudad-de-mexico-ventana-al-desarrollo-regional-de-los-pr/

SECRETARÍA DE COMUNICACIONES Y TRANSPORTES, SCT. (2017). Nuevo Aeropuerto Internacional de la Ciudad de México. SCT. Recuperado de: http://www.aeropuerto.gob.mx/ noticia-1.php

SCT Y GRUPO AEROPORTUARIO DE LA CIUDAD DE MÉXICO S.A. DE C.V. (2004). Estudio de Riesgo Modalidad Análisis de Riesgo del Nuevo Aeropuerto Internacional de la Ciudad de México Resumen Ejecutivo. México: Secretaría de Comunicaciones y Transportes - Grupo Aeroportuario de la Ciudad de México S.A de C.V-Instituto de Ingeniería UNAM.

SECRETARÍA DE GOBERNACIÓN. (2001). Decreto publicado el 22 de octubre de 2001 en el Diario Oficial de la Federación. Primera y segunda sección, México: SEGOB.

SECRETARÍA DE GOBERNACIÓN. (2014). Programa Nacional de Desarrollo Urbano 2014-2018. SEGOB. Recuperadode:http://dof.gob.mx/nota_detalle.php?codigo=5342867\&fecha=30/04/2014.

SEDESOL, INEGI Y CONAPO (2009). Zona Metropolitana del Valle de México. Toluca, Estado de México: Gobierno del Estado de México/Coespo.

SERRANO ARQUITECTOS. (2017). Propuesta del nuevo aeropuerto internacional de la ciudad de México. Obtenido el 26 de enero de 2018 en: http://www.archdaily.mx/mx/62752o/serrano-arquitectos-zaha-hadid-architects-presentan-su-propuesta-del-nuevo-aeropuerto-internacional-de-la-ciudad-de-mexico/54203a46co7a804806oooode 